\title{
QR CODE READER PADA SMARTPHONE ANDROID UNTUK APLIKASI LAYANAN RESTORAN
}

\author{
Dennise Adrianto'; Violitta Yesmaya ${ }^{2}$; Albertus Agung ${ }^{3}$; \\ Davin Timothy Ivander ${ }^{4}$ : Elysia ${ }^{5}$; Nico Natalie ${ }^{6}$ \\ 1, 2, 3, 4, 5, 6 Computer Science Department, School of Computer Science, Binus University \\ J1. K.H. Syahdan No. 9, Palmerah, Jakarta Barat 11480 \\ 1'dadrianto@binus.edu; ${ }^{2}$ vyesmaya@binus.edu; ${ }^{3}$ alagung@binus.edu; ${ }^{4}$ divander@binus.edu; \\ 5elysia@binus.edu; ${ }^{5}$ nico.natalie@yahoo.com
}

\begin{abstract}
The development of today's smartphone technology has a huge impact to the world of information technology and telecommunications. The emergence of a variety of applications for smartphones can improve the performance and effectiveness of an activity. Some restaurants have made use of smartphones in the business process, but only as a recording medium order or see a list of menus available in the restaurant. The purpose of this paper is to make the application as a whole that integrated the frontend and backend operations that help the process from ordering food, serving customer to managing restaurant data such as restaurant menus, employees, and transactions. The method used is the method of analysis (study of literature, analysis of similar applications, questionnaires, and interviews) and extreme programming design method. The results of this research is frontend application for food ordering and restaurant service and a backend system that has additional features such as restaurant profiles, restaurant menu data includes descriptions, recommended menu and images, promos, restaurant rating or menu rating, the waiter call feature, view bill and request features bill. The conclusion of this research is the developed application can help ordering process and restaurant services process in a restaurant with good customer satisfaction and good application performance.
\end{abstract}

Kata kunci: service, restaurant, QR Code, smartphone, android, application

\begin{abstract}
ABSTRAK
Perkembangan teknologi smartphone saat ini telah memberikan pengaruh yang sangat besar bagi dunia teknologi informasi dan telekomunikasi.Munculnya berbagai aplikasi untuk smartphone dapat meningkatkan kinerja dan keefektifan suatu aktivitas. Beberapa restoran telah memanfaatkan smartphone dalam proses bisnisnya, namun hanya sebagai media pencatat pesanan atau melihat daftar menu yang tersedia pada restoran. Tujuan dari penelitian ini adalah membuat aplikasi yang secara keseluruhan sanggup melayani kebutuhan pelanggan dalam memesan makanan dan pelayanan restoran serta backend restoran yang membantu proses operasional restoran dalam mengelola data menu, karyawan, dan transaksi. Metode penelitian yang digunakan adalah metode analisis (studi literatur, analisis aplikasi sejenis, kuesioner, dan wawancara) dan metode perancangan extreme programming. Hasil dari skripsi ini adalah aplikasi pemesanan makanan dan layanan restoran dan backend yang memiliki fitur-fitur tambahan lainnya seperti profil restoran, data menu yang lengkap meliputi deskripsi, rekomendasi dan gambar, promo, fitur rating terhadap restoran atau menu, fitur call waiter, fitur view bill dan request bill. Kesimpulan dari penelitian ini adalah aplikasi yang dikembangkan dengan fitur-fitur yang ada telah sangat membantu proses pemesanan dan layanan service pada restoran dengan kepuasan customer dan performa aplikasi yang baik.
\end{abstract}

Kata kunci: layanan, restoran, QR Code, smartphone, android, aplikasi 


\section{PENDAHULUAN}

Perkembangan teknologi smartphone saat ini telah memberikan pengaruh yang sangat besar bagi dunia teknologi informasi dan telekomunikasi. Munculnya berbagai aplikasi untuk smartphone dapat memberikan pilihan untuk meningkatkan kinerja dan keefektifan suatu aktivitas. Beragam aplikasi tidak hanya digunakan untuk meningkatkan kinerja suatu kegiatan, namun penerapannya dapat menjadi daya tarik tersendiri bila dibandingkan dengan perusahaan lain yang belum menerapkan hal tersebut.

Penggunaan smartphone merambah ke industri makanan, terutama restoran. Beberapa restoran telah memasukan teknologi smartphone dalam proses bisnisnya, contohnya saja restoran D'cost dan Vegas Hotdog. Restoran ini menggunakan smartphone sebagai media pencatat pesanan customer yang dilakukan oleh pelayan restoran atau untuk melihat daftar menu yang tersedia di restoran. Hal ini masih kurang efektif karena pelayan harus mendatangi customer untuk memberikan buku menu, lalu mencatat pesanan yang dipesan oleh customer. Hal tersebut akan memakan waktu yang cukup besar, apalagi jika kondisi restoran sedang ramai dan semua pelayan sedang sibuk melayani customer lain.

Didasari dengan kebutuhan aplikasi yang dapat memudahkan restoran dalam melakukan proses bisnisnya terutama dalam proses pemesanan makanan, maka penulis ingin membuat aplikasi pemesanan makanan dan layanan restoran pada smartphone berbasis Android dengan menggunakan QR Code. Law \& So (2010) menyatakan QR Code atau Quick Response Code merupakan bentuk evolusi dari kode batang (barcode) dari satu dimensi menjadi dua dimensi.

Pengguna yang memiliki smartphone dapat melihat menu yang disediakan oleh restoran dan melakukan pemesanan. Smartphone pengguna tidak harus terhubung dengan internet karena akan menggunakan jaringan hot-spot yang dimiliki oleh restoran. Aplikasi akan membaca QR Code yang disediakan dengan menggunakan kamera untuk mengubungkan smartphone pengguna secara otomatis ke jaringan restoran dan untuk identifikasi nomor meja.

Aplikasi akan dibangun pada platform Android karena Android bersifat open-source sehingga lebih mudah untuk dipelajari dan dikembangkan. Selain itu keberadaan smartphone untuk sistem operasi Android juga telah mendominasi penjualan smartphone dibandingkan dengan smartphone lainnya. Hal tersebut dapat dilihat dari data penjualan smartphone dalam jangka waktu satu tahun yaitu pada tahun 2012 - kuartal kedua tahun 2013, sistem operasi Android meningkat sebanyak 73.5\%. Hasil dari penelitian ini diharapkan dapat menyelesaikan masalah yang ada dan dapat menghasilkan sebuah aplikasi yang memberikan fitur-fitur menarik dan mendukung sistem pada restoran sehingga proses pemesanan makanan dan layanan menjadi lebih efisien.

\section{METODE}

Metode yang digunakan untuk memperoleh data dan informasi yang dibutuhkan dalam penelitian ini adalah: (1) Studi literatur yaitu metode yang dilakukan dengan cara mengumpulkan teori-teori dan penelitian sebelumnya yang berhubungan dengan pengembangan aplikasi dari buku, artikel, dan jurnal. (2) Analisis aplikasi sejenis yaitu metode yang dilakukan dengan cara menganalisa fitur-fitur dari aplikasi sejenis sehingga dapat membantu pengembangan fitur-fitur pada aplikasi yang akan dikembangkan. (3) Kuesioner yaitu metode yang dilakukan dengan cara membagikan kuesioner untuk mendapatkan informasi yang dapat membantu pengembangan aplikasi meliputi kuesioner kebutuhan pengguna dan kuesioner evaluasi aplikasi. (4) Wawancara yaitu metode yang dilakukan dengan cara menyajikan sejumlah pertanyaan kepada pakar Information Technology (IT) dan pengurus restoran sehingga dapat membantu evaluasi aplikasi. (5) Observasi yaitu metode yang dilakukan dengan melakukan pengamatan langsung terhadap restoran seperti pengamatan sistem ordering menggunakan smartphone yang diterapkan restoran. 


\section{Tinjauan Pustaka}

Restoran berasal dari kata restaurer (Perancis) yang berarti restore atau restorasi yang dalam Bahasa Indonesia berarti memperbaiki atau memulihkan. Restoran adalah suatu tempat yang menyediakan makanan dan atau minuman dan memungut bayaran (for-profit food service), yang juga mencakup rumah makan, bar, kafetaria, catering dan yang termasuk jasa boga lainnya (Ninemeir \& Hayes, 2006).

Menurut Gronroos (dalam Ratminto dan Winarsi, 2005), pelayanan adalah suatu aktivitas atau serangkaian aktivitas yang bersifat tidak kasat mata atau tidak dapat diraba dan terjadi sebagai akibat adanya interaksi antar konsumen dengan karyawan atau hal-hal lain yang disediakan oleh organisasi pemberi pelayanan untuk memecahkan permasalahan konsumen atau pelanggan. Menurut Sinambela (2006), pelayanan adalah setiap kegiatan yang menguntungkan dalam suatu kumpulan atau kesatuan, dan menawarkan kepuasan meskipun hasilnya tidak terkait pada suatu produk secara fisik. Menurut Napitupulu (2007), pelayanan adalah serangkaian kegiatan suatu proses pemenuhan kebutuhan orang lain secara lebih memuaskan berupa produk jasa dengan sejumlah ciri seperti tidak terwujud, cepat hilang, lebih dapat dirasakan daripada memilki, dan pelanggan lebih dapat berpartisispasi aktif dalam proses mengkonsumsi jasa tersebut.

Prosedur pelayanan pada restoran merupakan kegiatan operasional sebelum restoran dibuka sampai restoran ditutup. Kegiatan ini meliputi semua usaha petugas restoran dalam memberikan pelayanan kepada tamu, baik persiapan tamu datang sampai tamu meninggalkan restoran. Untuk menunjang keberhasilan dalam melaksanakan tugas seorang pegawai restoran harus mengetahui dan memahami prosedur kerja pada saat pelayanan makanan dan minuman berlangsung (Almarogi, 2013). Keberhasilan selama restoran beroperasi tergantung bagaimana petugas restoran dapat melaksanakan pekerjaan dengan baik. Pekerjaan ini menyangkut bagaimana petugas melayani tamu sehingga tamu merasa puas dan senang atas pelayanan yang didapatkan. Untuk mempertemukan kedua keinginan yang berbeda antara pelanggan dengan pemilik restoran, maka diperlukan kunci keberhasilan antara lain: ketepatan, kecekatan, kejelian, kepekaan dari sumber tenaga yang profesional dengan sistem, dan tahapan pelayanan sehingga dapat memenuhi keinginan pelanggan.

Menurut Pressman (2010), agile development disusun oleh Kent Beck dan 16 orang lainnya, yang menyatakan bahwa agile development berisi sekumpulan metodologi dalam merancang perangkat lunak yang mementingkan kepuasan customer dan penyampaian perangkat lunak secara berkala; tim proyek yang tidak terlalu besar dan memiliki motivasi tinggi; dan mementingkan simplicity. Proses pengembangan agile menekankan delivery (proses) dibanding dengan analisis dan desain serta komunikasi yang aktif antara customer dengan developer.

Dalam manifesto tersebut juga menyatakan bahwa untuk merancang perangkat lunak yang baik, dibutuhkan empat hal utama yaitu: (1) Mementingkan interaksi antar individu dibandingkan dengan proses dan tools. (2) Mementingkan perangkat yang bekerja dengan baik dibandingkan dengan kelengkapan dokumentasi. (3) Mementingkan kolaborasi dengan sesama users dibandingkan dengan kontrak yang sudah dibuat sebelumnya. (4) Merespon perubahan yang terjadi, tidak terikat pada rencana yang dibuat sebelum nya.

Selain membuat manifesto, Agile Development juga mendefisinikan 12 prinsip agility yaitu: (1) Prioritas utama adalah untuk memuaskan customer dengan memberikan pelayanan perangkat lunak yang baik dari awal dan berkelanjutan. (2) Menerima perbuahan kebutuhan, meskipun terjadi di akhir pengembangan. (3) Memberikan hasil perangkat lunak secara berkala, dalam hitungan minggu atau bulan. (4) Pengembang perangkat lunak dan orang-orang yang memiliki kepentingan bekerja sama selama proyek berlangsung. (5) Membangun proyek diantara orang-orang yang memiliki motivasi. Menyediakan lingkungan dan dukungan yang mereka butuhkan, dan percaya mereka dapat 
menyelesaikan pekerjaan yang ada. (6) Metode paling efektif dalam menyampaikan informasi kepada para pengembang adalah dengan komunikasi langsung. (7) Perangkat lunak yang bekerja dengan baik adalah alat ukur utama dari kemajuan proyek. (8) Agile process mendukung pengembangan berkelanjutan. Para sponsor, pengembang dan users bisa bebas menjaga kestabilan proyek. (9) Memberikan perhatian secara terus-menerus kepada keunggulan teknis yang dimiliki dan desain yang baik dapat meningkatkan ketangkasan. (10) Kesederhanaan itu penting. (11) Arsitektur, kebutuhan, dan desain yang baik didapat dari tim yang dapat mengatur dirinya sendiri. (12) Secara berkala, tim merefleksikan apakah yang dikerjakan sudah efektif dan mencari cara agar lebih efektif serta melakukannya dengan segera.

Beberapa hal penting yang harus dimiliki seseorang agar dapat menerapkan konsep Agile Development adalah harus memiliki kompetensi, fokus pada tujuan, bisa berkolaborasi dengan anggota tim, bisa membuat keputusan, dapat memecahkan fuzzy problem, percaya dan saling menghormati anggota tim, serta memiliki kemampuan untuk mengatur diri dan organisasi.

Menurut Pressman (2010) Extreme Programming (XP) merupakan salah satu metode pengembangan perangkat lunak yang termasuk dalam agile development. Ada 5 hal penting yang menjadi dasar dari metode ini: (1) Communication. Komunikasi yang efektif antara pengembang dengan pihak-pihak yang memiliki kepentingan sangat penting untuk menentukan fitur dan fungsi dari perangkat lunak yang akan dibuat, serta memberikan pandangan kepada pengembang sesuai dengan pandangan pengguna perangkat lunak. (2) Simplicity. Metode XP membatasi pengembang untuk merancang hanya untuk kebutuhan saat ini, daripada kebutuhan yang akan datang. Hal ini bertujuan agar dapat menghasilkan rancangan yang sederhana, yang mudah diimplementasikan pada code. Jika rancangan harus dikemabangkan, dapat dilakukan dilain waktu (refactored). (3) Feedback. Umpan balik didapat dari tiga sumber, yang pertama adalah implementasi perangkat lunak itu sendiri, customer, dan team pengembang lainnya. Hal ini bertujuan untuk mengetahui kemajuan dari proses dan kualitas dari perangkat lunak yang dibangun agar hal-hal yang menjadi masalah dalam proses pembangunan dapat diketahui dari awal. Setiap feedback yang diterima, ditanggapi dengan melakukan tes dan dilakukan secepatnya. (4) Courage. Courage adalah komitmen untuk selalu melakukan design dan coding untuk hari ini dan bukan untuk esok, dan menyadari bahwa kebutuhan esok akan bisa berubah secara dramatis, sehingga menuntut pengembang untuk melakukan refactor. (5) Respect. Dengan mengikuti langkah-langkah diatas, tim harus menghormati anggota tim lainnya, tidak boleh melalukan perubahan yang dapat merusak kompikasi dan memperlambat kerja tim.

Menurut Pressman (2010), Extreme Programming (XP) menggunakan pendekatan objectoriented dan mencakup seperangkat aturan yang terjadi dalam 4 kerangka kegiatan: planning, design, coding, and testing.

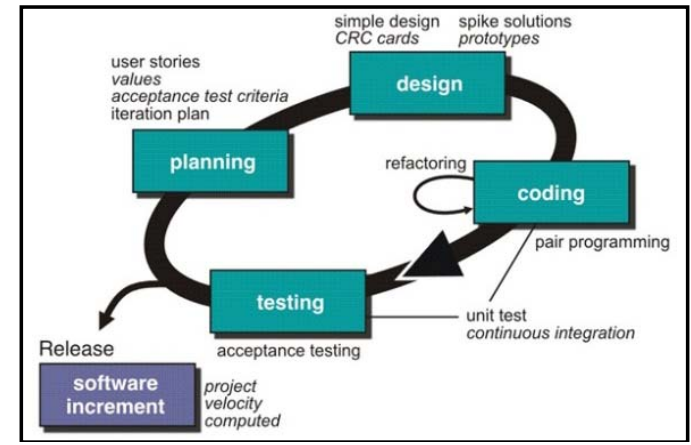

Gambar 1 Metode Pendekatan Extreme Programming (Sumber: www.jptutorials.co.in, 2013) 
Planning dimulai dengan mengumpulkan kebutuhan yang memungkinkan para anggota dari tim XP dapat memahami konteks bisnis dari perangkat lunak yang akan dibuat dan mendapat wawasan yang luas untuk output apa yang diperlukan serta fitur-fitur utama dari perangkat lunak. Tahap ini akan mengarah pada pembuatan "stories" yang menggambarkan output yang dibutuhkan, fitur, dan fungsi dari perangkat lunak yang akan dibuat.

Metode XP mengikuti aturan KIS (KeepItSimple). Desain yang sederhana selalu diutamakan dibandingkan dengan representasi yang kompleks. Jika terdapat design yang sulit, XP akan menerapkan SpikeSolution, dimana pembuatan design dilakukan segera, dan dibuat langsung ke tujuannya. XP juga mendukung adanya refactoring dimana kita dapat melakukan perubahan pada kode program untuk disederhanakan tanpa merubah cara kode tersebut bekerja.

Setelah "stories" sudah dirancang dan desain awal sudah selesai, tim tidak langsung memulai code, tetapi terlebih dahulu merancang beberapa unittest yang digunakan untuk menjalankan "stories" dan disertakan pada softwarerelease saat itu. Setelah itu, pengembang focus untuk mengimplementasikannya. XP juga menerapkan Pair Programming yaitu proses pengembangan program yang dilakukan secara berpasangan. Dua orang bekerja sama dalam satu komputer untuk menulis kode. Hal ini memberikan real-timeproblemsolving dan real-timequalityassurance.

Pada tahap testing dilakukan pengujian kode pada unittest yang telah dibuat sebelumnya. Pada metode XP dilakukan acceptance test atau biasa disebut customer test.Tes ini diberikan kepada customer akan menggunakan fitur dan fungsi sistem yang akan dibuat.

Law, C. \& So, S. (2010) menyatakan bahwa QR Code merupakan bentuk dua dimensi dari barcode. QR Code dikembangkan oleh Denso Wave yang digunakan untuk mendata sparepart kendaraan pada tahun 1994. QR merupakan singkatan dari QuickResponse. QR Code dapat dibaca melalui smartphone yang sudah dilengkapi kamera dan pemindai QR. Informasi seperti URL, SMS, informasi kontak, dan teks dapat disimpan matriks 2 dimensi.

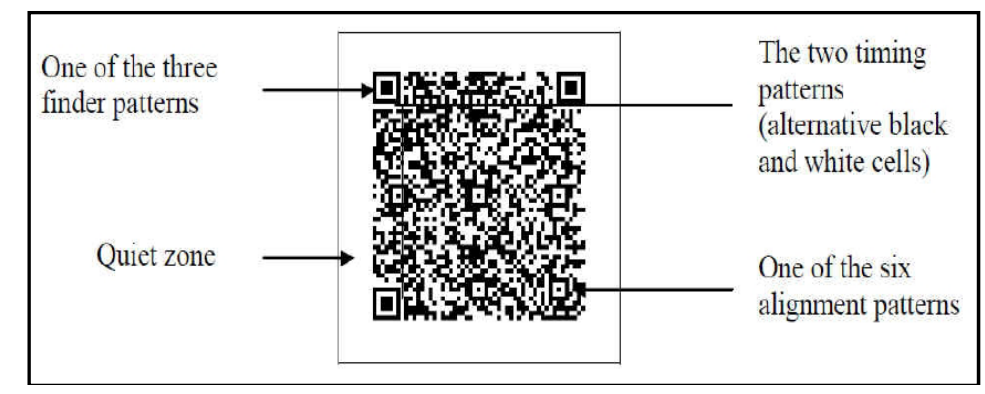

Gambar 2 Contoh QR Code

QR Code mampu menyimpan 7,089 angka, 4,296 alfanumerik, 2,965 bytes, 1,817 Kanji. Kapasitas data yang disimpan lebih banyak dari pada barcode karena dapat menyimpan informasi secara vertikal dan horizontal. QR Code dapat dibaca dari berbagai arah $\left(360^{\circ}\right)$ melalui pola deteksi yang terletak di tiga sudut seperti yang ditunjukan pada Gambar 2. 


\section{HASIL DAN PEMBAHASAN}

Sampai saat ini, teknologi menjadi asset strategis yang penting bagi industri restoran untuk meningkatkan layanan dan produk untuk mempertahankan daya saing.Hal ini telah ditekankan pada industri restoran harus mengatasi kekurangan teknologi proaktif dan komprehensif jika berharap untuk mendapatkan keuntungan dari revolusi pasar yang dipengaruhi oleh kemajuan teknologi.Hanya mereka yang bisa mengikuti perkembangan teknologi yang mampu mempertahankan customer yang sudah ada, membuka bisnis baru, dan mendapatkan pangsa pasar.

Pengaruh teknologi terhadap industri restoran tidak hanya pada bagaimana produk yang dihasilkan, tetapi juga bagaimana produk disajikan pada menu, sehingga inovasi pada penyajian menu adalah masalah yang menarik bagi para pengelola restoran.Menu dianggap sebagai alat pemasaran dan iklan cetak karena menyampaikan pesan kepada customer dan mempengaruhi penjualan langsung.

Sebagai sumber utama informasi tentang restoran, idealnya, menu desain yang tepat akan memperkuat citra, memberikan ekpektasi kepada customer tentang makanan yang dipesan serta kualitasnya. Studi yang dilakukan oleh Reynolds et. al. (2005) meneliti apakah font, warna, tata letak, dan desain menjadi faktor penting yang mempengaruhi perilaku customer, dan hasil menunjukkan bahwa teknik desain menu saat ini tidak dapat secara efektif menarik perhatian customer dan pada akhirnya akan mempengaruhi kinerja restoran. Oleh karena itu, perubahan yang lebih luas dalam desain menu dan pemasaran produk mungkin diperlukan untuk meningkatkan cek rata-rata. Hal ini dapat secara efektif dicapai melalui penerapan teknologi.

\section{Sistem Pemesanan Makanan Menggunakan PDA}

Kemajuan Teknologi Informasi dan Komunikasi membuat peningkatan jumlah industri yang menggunakan teknologi untuk menunjang aktivitas. Dalam bidang restoran, PDA (Personal Digital Assistant) digunakan untuk mengganti sistem pemesanan makan tradisional yang masih menggunakan kertas dan pena. Pada sistem order ini, customer restoran yang datang akan diantar ke tempat duduk, lalu memberikan buku menu. Pelayan restoran akan pergi ke meja lain sambil menunggu customer untuk memilih menu. Ketika customer sudah siap untuk melakukan order, pelayan akan mencatat order menggunakan PDA. Order lalu akan dikirim ke dapur untuk segera diproses. Ketika customer sudah selesai makan dan ingin meminta bill, pelayan akan mengecek order customer melalui PDA, lalu membuat bill tersebut.

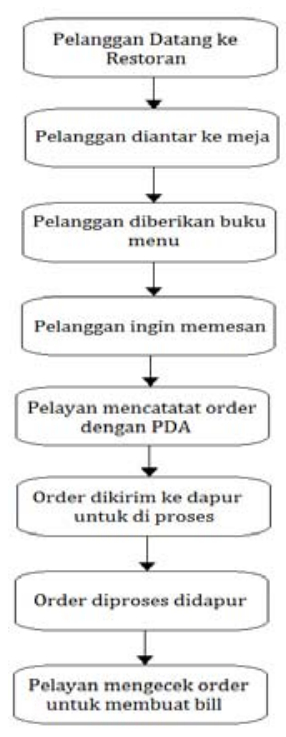

Gambar 3 Proses Order Makanan Menggunakan PDA 
Tetapi, banyak kelemahan yang dengan sistem ini. Contohnya penyajian daftar menu masih menggunakan cara konvensional (Menu cetak). Jika ada perubahan terhadap menu seperti harga, ketersediaan, promosi dan lainnya harus dilakukan secara manual. Daftar menu tersebut hanya memiliki sedikit informasi tentang menu, sehingga pelayan harus bisa menyediakan informasi tentang menu-menu tersebut.

\section{Use Case Diagram}

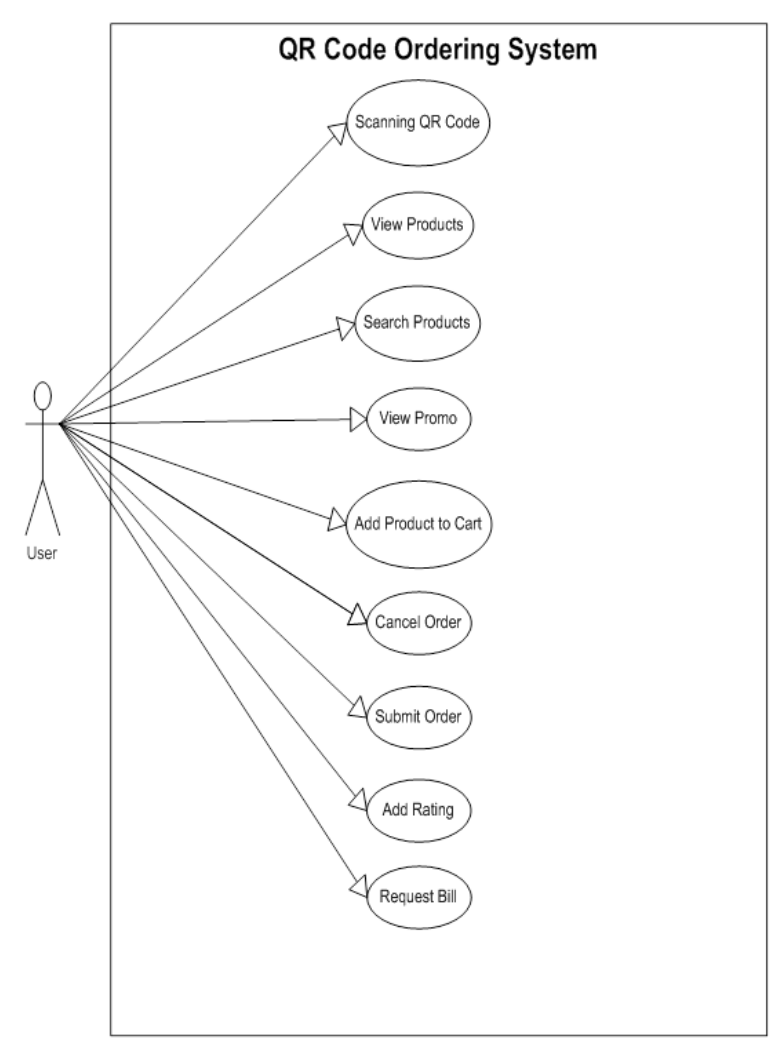

Gambar 4 Use Case Diagram (Front End)

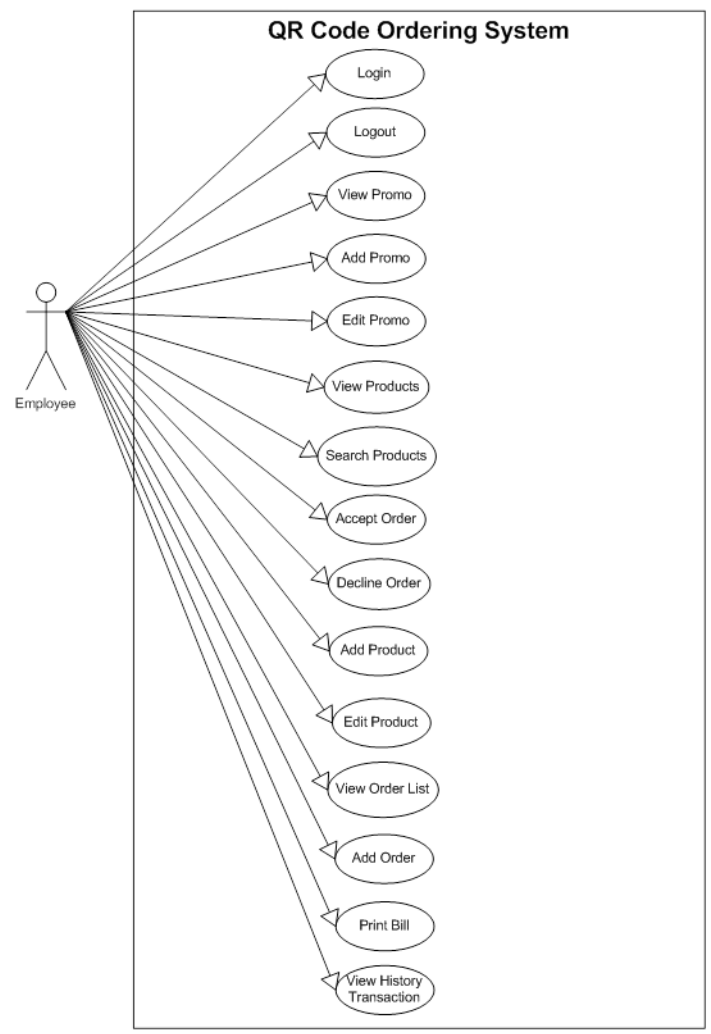

Gambar 5 Use Case Diagram (Back End) 


\section{Class Diagram}

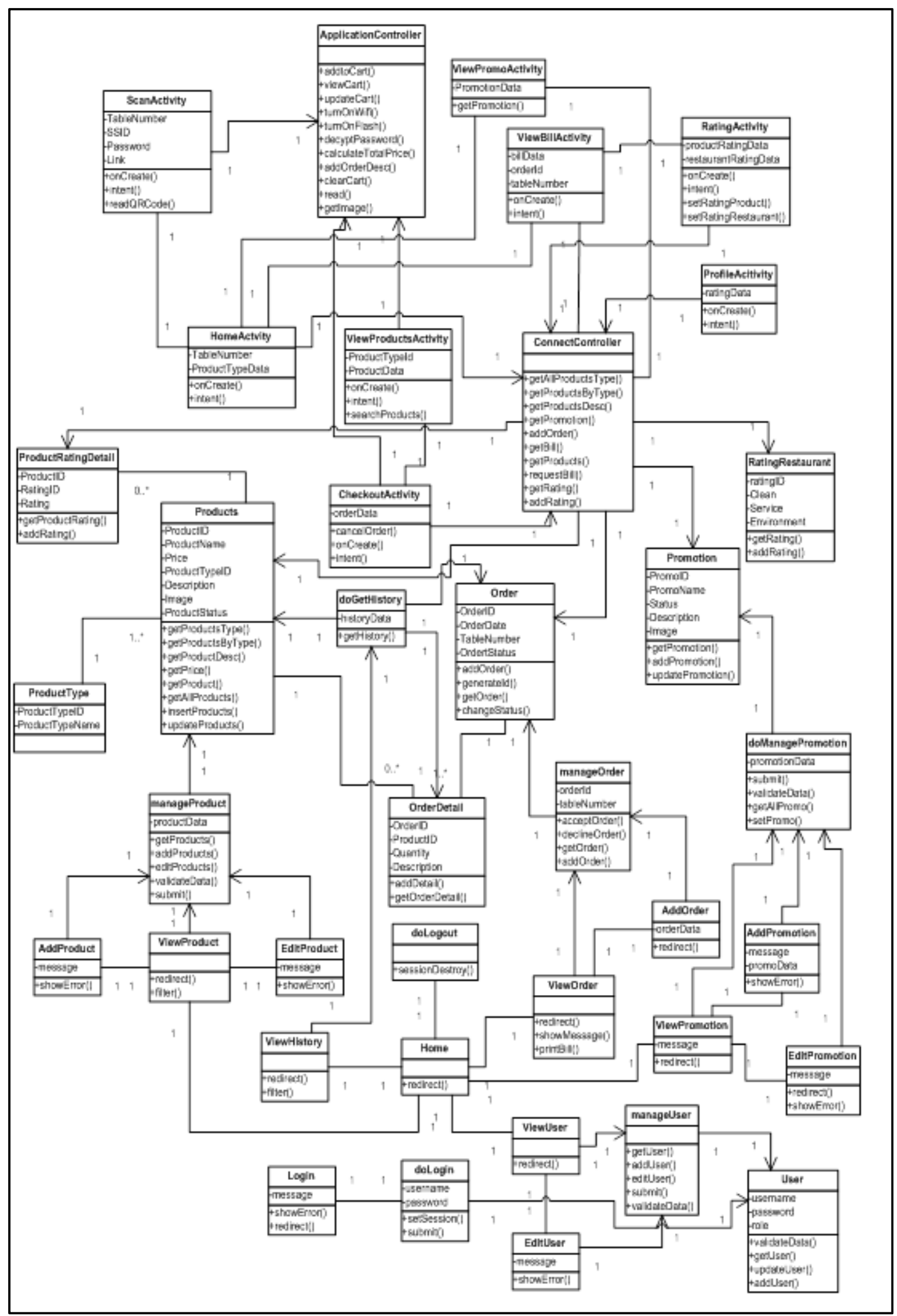

Gambar 6 Class Diagram 


\section{Perbandingan dengan Aplikasi Sejenis}

\section{Ravintola}

Ravintola adalah sebuah piranti lunak manajemen restoran/software restoran. Salah satu restoran yang menggunakan aplikasi ini adalah Vegas Hotdog. Restoran Vegas Hotdog adalah sebuah cafe yang terletak di mall Central Park, Jakarta Barat yang menyajikan makan tradisional Amerika, dengan menu utama hot dog. Restoran ini cukup menarik perhatian customer dengan konsep pemesanannya yang menggunakan iPad.

Ketika customer datang dan memilih tempat duduk, karyawan restoran akan membawakan ipad dan meng-input nomor meja di ipad tersebut sebelum menyerahkannya ke customer. Berikut user interface dari aplikasi ravintola yang diimplementasikan di restoran Vegas Hotdog :

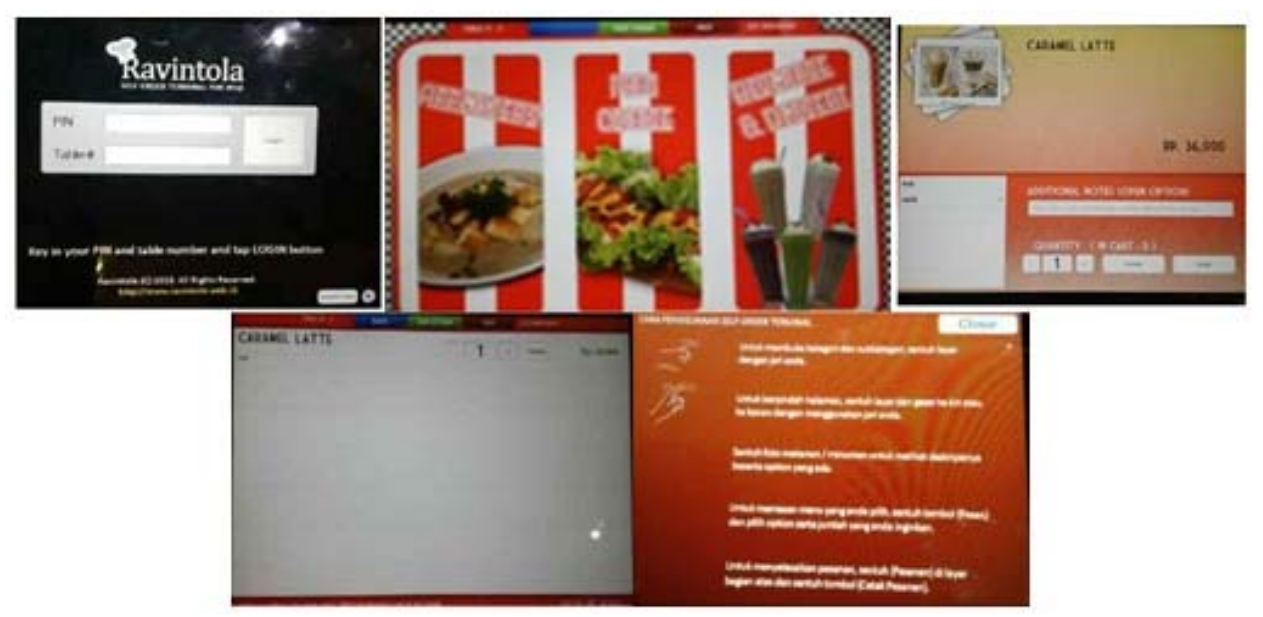

Gambar 7 Tampilan Aplikasi Ravintola

Customer dapat melihat menu dan meng-input order melalui ipad tersebut dengan panduan dari karyawan. Setelah selesai, iPad akan dibawa kembali oleh karyawan. List order akan di-print dan diberikan ke bagian dapur. Customer tidak menerima copy-an list order yang telah dipesan sebelumnya.

Penambahan pesanan harus dilakukan menggunakan iPad seperti proses pemesanan yang pertama. Customer harus memanggil karyawan dan menunggu giliran pemakaian iPad. Customer meminta tagihan dengan memanggil karyawan. Karyawan akan mencetak tagihan dan memberikannya kepada customer. Jika ada penambahan order, tagihan akan tercetak lebih dari satu tagihan yang diklip menjadi satu.

\section{QikServe}

QikServe adalah aplikasi pemesanan makanan yang menggunakan model e-commerce web dengan aplikasi smartphone untuk memungkinkan customer memesan makanan di meja tempat mereka duduk melalui smartphone. Customer harus melakukan scanning pada QR Code yang terdapat pada meja makan restoran sebelum melakukan pemesanan. QR Code tersebut menyimpan informasi lokasi restoran dan meja. QikServe dapat digunakan terus menerus untuk melakukan pemesanan selanjutnya misalnya minuman. Setelah menempatkan pesanan, sistem menyajikan konfirmasi bahwa pesanan telah diterima. 
Metode pembayaran dapat dilakukan melalui waiter atau counter, PayPall, credit atau debit card. Pesanan dikirimkan ke dapur dan bar staf melalui portal online dan / atau GPRS printer dan / atau e-mail dan/atau integrasi POS. Sistem ini terintegrasi dengan media sosial seperti Facebook dan Twitter. Customer dapat berbagi check-in, meninjau restoran, dan mengundang teman.

Berikut user interface dari aplikasi QikServe:
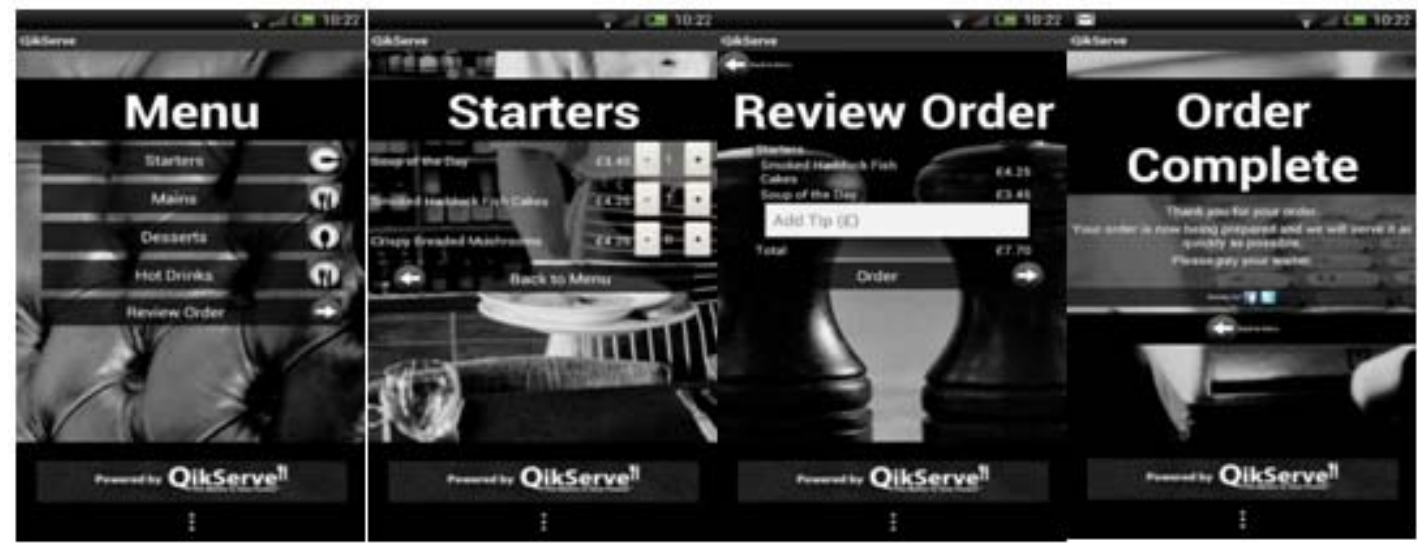

Gambar 8 Tampilan Aplikasi QikServe

(sumber: http://www.androidpit.com/app/com.qikserve)

Berikut ini adalah tabel perbandingan antara aplikasi XServe dengan aplikasi sejenis:

Tabel 1 Perbandingan XServe dengan aplikasi sejenis

\begin{tabular}{|c|c|c|c|c|}
\hline & Fitur & $\begin{array}{c}\text { Ravintola } \\
\text { (Vegas Hotdog) }\end{array}$ & QikServe & XServe \\
\hline \multirow{3}{*}{ Restoran } & Profil & $\times$ & $x$ & $\sqrt{ }$ \\
\hline & Rating & $x$ & $x$ & $\sqrt{ }$ \\
\hline & Pencarian restoran supportedterdekat & $\times$ & $\times$ & $\sqrt{ }$ \\
\hline \multirow{8}{*}{ Menu } & Promo (info diskon, menu baru, dll) & $\times$ & $x$ & $\sqrt{ }$ \\
\hline & Pencarian menu & $\times$ & $\times$ & $\sqrt{ }$ \\
\hline & Kategori & $\sqrt{ }$ & $\sqrt{ }$ & $\sqrt{ }$ \\
\hline & Gambar & $\sqrt{ }$ & $\sqrt{ }$ & $\sqrt{ }$ \\
\hline & Harga & $\sqrt{ }$ & $\sqrt{ }$ & $\sqrt{ }$ \\
\hline & Keterangan Menu & $\sqrt{ }$ & $\sqrt{ }$ & $\sqrt{ }$ \\
\hline & Recommended Menu by Restaurant & $\times$ & $\times$ & $\sqrt{ }$ \\
\hline & Rating Menu by customer & $x$ & $\times$ & $\sqrt{ }$ \\
\hline \multirow{4}{*}{ Order } & UpdateOrder & $\sqrt{ }$ & $\sqrt{ }$ & $\sqrt{ }$ \\
\hline & Multiple Order in One Bill & $x$ & $x$ & $\sqrt{ }$ \\
\hline & Specialrequestorinstruction & $\sqrt{ }$ & $\sqrt{ }$ & $\sqrt{ }$ \\
\hline & Total Harga & $x$ & $\sqrt{ }$ & $\sqrt{ }$ \\
\hline \multirow{2}{*}{ Lainnya } & Call Waiter & $x$ & $x$ & $\sqrt{ }$ \\
\hline & Help & $\sqrt{ }$ & $\times$ & $\sqrt{ }$ \\
\hline
\end{tabular}




\section{Evaluasi}

\section{Evaluasi Aplikasi Berdasarkan Lima Faktor Manusia Terukur}

Berdasarkan hasil kuesioner dan wawancara yang diperoleh, berikut hasil evaluasi aplikasi berdasarkan lima faktor manusia terukur: (1) Waktu belajar. Aplikasi pemesanan makanan dan layanan restoran XServe sangat mudah digunakan. Hal tersebut dapat disimpulkan dari pertanyaan nomor 13 dalam kuesioner evaluasi mengenai kemudahan dalam penggunaan aplikasi. Dengan begitu, dapat disimpulkan bahwa waktu belajar yang diperlukan untuk aplikasi XServe sedikit. (2) Kecepatan kinerja. Kecepatan kinerja aplikasi pemesanan makanan dan layanan restoran XServe sudah baik. Hal ini dapat disimpulkan dari pertanyaan kuesioner evaluasi nomor 7 mengenai kecepatan dalam pengiriman pesanan (submitorder) dan pertanyaan wawancara evaluasi nomor 3 mengenai performa aplikasi. (3) Tingkat kesalahan user. Aplikasi pemesanan makanan dan layanan restoran XServe sangat mudah digunakan sehingga tingkat kesalahan yang mungkin diperbuat userakan sangat kecil. Hal tersebut dapat disimpulkan dari hasil pertanyaan kuesioner evaluai nomor 13 mengenai kemudahan dalam penggunaan aplikasi. (4) Daya ingat. Secara keseluruhan, aplikasi pemesanan makanan dan layanan restoran XServe mudah digunakan dan mudah dimengerti sehingga mudah diingat. Hal ini juga dapat disimpulkan dari hasil kuesioner evaluasi nomor 12 mengenai menu help yaitu menu ini dinilai sangat membantu responden sebagai panduan pemakaian aplikasi sehingga pengguna tidak perlu mengingat cara penggunaan aplikasi. (5) Tingkat kepuasan subjektif. Aplikasi pemesanan makanan dan layanan restoran XServe dinilai baik dari segi fitur atau fungsionalitas, performa, dan desain (user interface). Hal ini dapat dilihat dari kesimpulan dari kuesioner evaluasi aplikasi dan hasil wawancara. Sebagian besar responden juga sangat tertarik untuk menggunakan aplikasi XServe. Ini membuktikan bahwa tingkat kepuasan subjektif sudah baik.

\section{Evaluasi Aplikasi Terhadap Sepuluh Prinsip Perancangan Mobile Application}

Stark (2012) mengemukakan mengenai 10 prinsip perancangan mobile application, aplikasi XServe akan dievaluasi sejauh mana aplikasi memenuhi sepuluh prinsip tersebut. Sepuluh prinsip tersebut adalah Mobile Mindset, Mobile Context, Global Guidelines, Navigation Model, User Input, Gesture, Orientation, Communication, Launching dan First Impression.

Dari prinsip Mobile Mindset, aplikasi yang dikembangkan berfokus pada pemesanan makanan dengan fitur-fitur tambahan sebagai pendukung proses pemesanan makanan. Desain sederhana sehingga mudah digunakan. User interface aplikasi menggunakan dominasi warna hijau dan orange yang memberikan kesan unik dan menarik. Dalam hal Mobile Contexts, aplikasi yang dikembangkan memiliki fitur yang telah disesuaikan dengan target user, yaitu user yang menggunakan mobile application pada saat user ataupun lingkungan sekitar dalam keadaan sibuk. Aplikasi yang dikembangkan dapat melaksanakan tugas dengan cepat, dapat diandalkan dan dapat diselesaikan dengan satu tangan seperti fitur callwaiter.

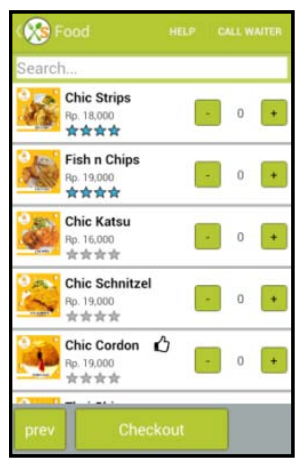

Gambar 9 Contoh Mobile Mindset

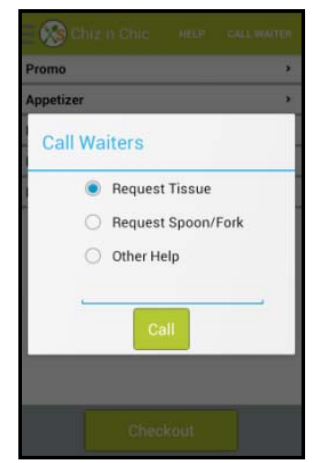

Gambar 10 Contoh Mobile Context 
Dari sisi Global Guidelines, aplikasi yang dikembangkan telah mengikuti pedoman umum yang ada, seperti tingkat responsif yang tinggi terhadap tindakan user, tampilan yang detail dan menarik, mengutamakan kenyamanan ibu jari dalam berinteraksi, letak user interface yang sesuai, content yang gampang diakses dan dimengerti, peletakan kontrol dibawah isi, mengurangi penggunaan scrolling. Berdasarkan Navigation Models, aplikasi yang dikembangkan menggunakan model navigasi drilldown agar lebih memudahkan user melihat menu yang berupa daftar (list) dan detail dalam hierarki konten.

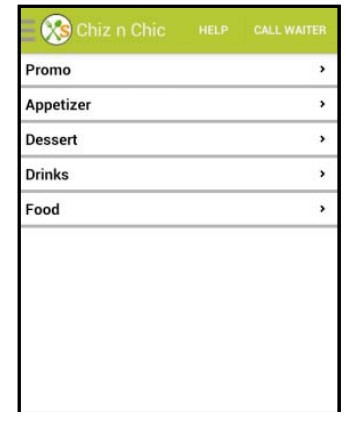

Gambar 11 Contoh Global Guidelines

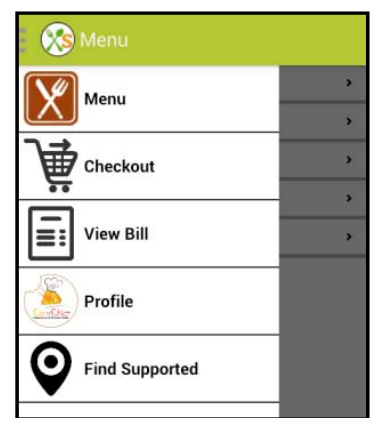

Gambar 12 Contoh Navigation Models

Berdasarkan User Input, aplikasi yang dikembangkan tidak membutuhkan banyak pengetikan, sehingga keyboard yang ditampilkan untuk pengetikan hanya portrait, tidak mendukung landscapekeyboard. Dari sisi Gestures, secara umum, fitur-fitur aplikasi yang dikembangkan dapat diakses dengan click yang umumnya digunakan pada aplikasi yang dikembangkan di Android sehingga user tidak kesulitan untuk menemukannya.

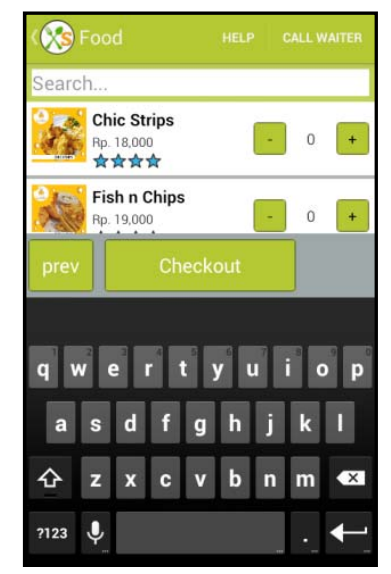

Gambar 13 Contoh User Input

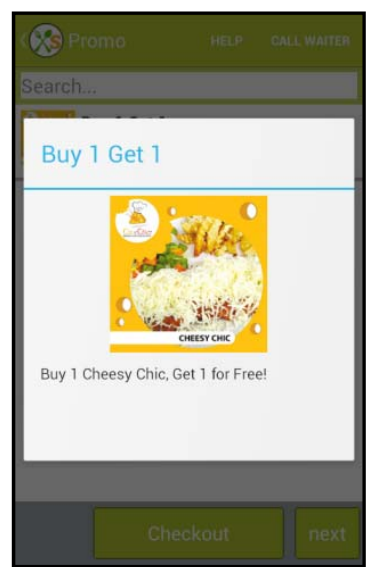

Gambar 14 Contoh Gesture

Dari sisi Orientation, aplikasi yang dikembangkan menggunakan orientasi portrait. Penguncian orientasi telah dilakukan dengan orientasi portrait karena tidak ada kebutuhan pengetikan yang banyak dari aplikasi, sehingga tidak membutukan orientasi landscape. Berdasarkan Communication, aplikasi yang dikembangkan diusahakan untuk berkomunikasi dengan user. Beberapa jenis komunikasi yang digunakan yaitu permberian feedback terhadap setiap aksi user seperti perubahan warna menu ketika dipilih agar user mengetahui menu yang telah dipilih. Selain itu juga terdapat konfirmasi ketika user melakukan aksi tertentu, misalnya ketika user melakukan penghapusan list order yang akan di-submit (clear cart), aplikasi memuncul sebuah confirmation dialog box yang menanyakan keyakinan user untuk menghapus. 


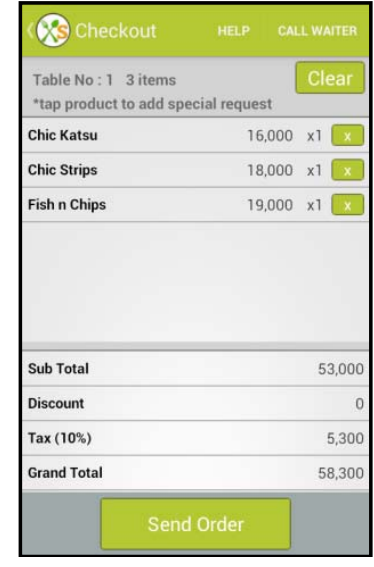

Gambar 15 Contoh Orientation

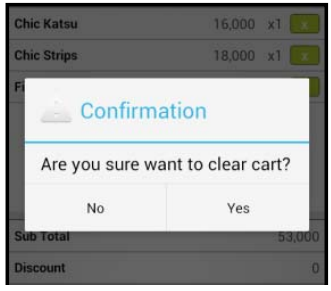

Gambar 16 Contoh Communications

Dari sisi Launching, ketika user membuka kembali aplikasi yang telah digunakan sebelumnya (launching kembali), aplikasi akan terbuka pada tampilan operasi terakhir. Hal ini memberi kesan bahwa aplikasi cepat dan responsif. Berdasarkan First Impression, kesan pertama pada aplikasi sangatlah penting. Icon mempengaruhi kesan pertama pada aplikasi yang dikembangkan. Icon aplikasi yang dikembangkan di desain simpel, menarik, kontras serta menggambarkan fungsi dari aplikasi.

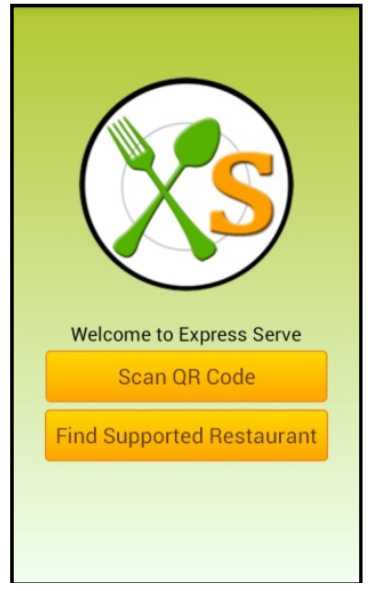

Gambar 17 Contoh Launching

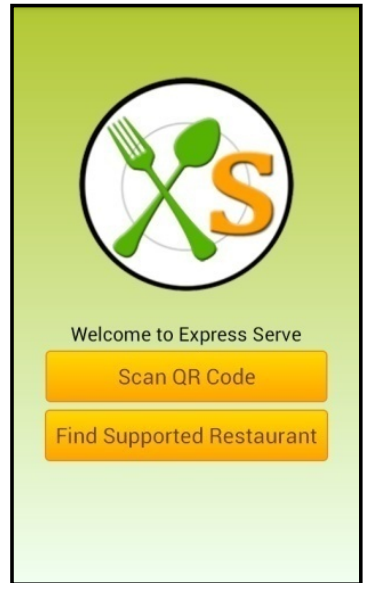

Gambar 18 Contoh First Impresion

\section{Evaluasi Aplikasi Berdasarkan Hasil Wawancara}

Evaluasi ini dilakukan dengan melakukan demo aplikasi kepada 6 orang pakar IT yang meliputi para pekerja IT (Head dan staff bidang research and development dan operation) dan staff pengajar bidang IT (dosen dan asisten). Para pakar IT ini diwawancara dengan pertanyaan-pertanyaan yang berkaitan dengan aplikasi yang dikembangkan. Berikut hasil wawancara yang diperoleh:

Menurut Anda, apa kekurangan dan kelebihan aplikasi pemesanan makanan dan layanan restoran XServe?

Kelebihan dari aplikasi XServe adalah adanya tampilan menu yang detail (seperti harga, gambar, recommended dan deskripsi menu), fitur special request yang memungkinkan customer 
untuk menyampaikan permintaan tertentu pada makanan yang dipesan (Contohnya tidak mau pake cabe), fitur view bill yang memungkinkan customer untuk melihat jumlah tagihan tanpa harus meminta tagihan terlebih dahulu kepada pelayan. fitur call waiter yang dapat memanggil pelayan dengan atau tanpa permintaan tertentu, fitur profil restoran, fitur rating pada menu dan restoran yang memungkinkan customer untuk melihat atau memberikan penilaian dan fitur find supported restaurant yang membantu customer untuk mengetahui restoran-restoran yang support menggunakan aplikasi pemesanan makanan self service XServe. Selain itu, aplikasi ini juga mendukung multiple order yang memungkinkan customer melakukan send order lebih dari satu kali di nomor meja yang sama dan atau dengan device yang berbeda-beda. Multiple order ini akan masuk ke dalam tagihan yang sama selama belum melakukan pembayaran pada transaksi sebelumnya.

Kekurangan dari aplikasi XServe adalah tidak adanya fitur pemberian komentar ketika customer melakukan rating pada menu atau restoran, search menu yang dilakukan hanya berdasarkan kategori atau nama tertentu dan akan lebih baik jika ditambahkan berdasarkan tag tertentu dan perlu diperhatikan ketika device gagal terhubung ke wi-fi restoran. Pada special request tiap menu perlu adanya informasi pendukung tentang komposisi atau topping tertentu yang disediakan untuk menu tersebut, sehingga customer mengetahui custom apa saja yang bisa mereka pilih.

Secara keseluruhan, bagaimana fungsionalitas dari aplikasi pemesanan makanan dan layanan restoran XServe?

Secara keseluruhan, aplikasi ini sudah memenuhi kebutuhan utama yaitu pemesanan makanan dan layanan pada restoran. Fungsionalitas sudah cukup baik. Fitur-fitur pendukung tambahan lainnya juga cukup membantu. Special case perlu diperhatikan untuk pengembangan aplikasi lebih lanjut.

Secara keseluruhan, bagaimana performa dari aplikasi pemesanan makanan dan layanan restoran XServe?

Dilihat dari segi kecepatannya, performa aplikasi sudah cukup baik, tidak berat dan memberikan respon yang cepat (responsif). Belum ditemukan adanya pengiriman order atau permintaan lainnya yang gagal, namun perlu diperhatikan lagi performa aplikasi jika ada banyaknya customer yang melakukan pengiriman order atau permintaan lainnya.

Menurut Anda, apakah desain dari aplikasi pemesanan makanan dan layanan restoran "XServe" sudah sesuai?

Desain aplikasi pemesanan makanan XServe sudah sesuai dan cukup menarik dari segi warna maupun icon. Desain aplikasi juga sederhana dan mudah digunakan dan lebih baik jika warna aplikasi dapat di-custom oleh restoran sehingga warna aplikasi dapat disesuaikan dengan tema warna restoran masing-masing.

\section{Evaluasi Kuesioner}

Berdasarkan hasil kuesioner evaluasi yang diperoleh, dapat disimpulkan bahwa responden sudah merasa puas dengan aplikasi XServe, baik dari segi user interface, kecepatan, fitur-fitur baru yang ditawarkan serta fitur pendukung lainnya. Fitur-fitur tersebut sudah sangat membantu dalam pencarian restoran terdekat, pemesanan makanan, pemanggilan pelayan sampai dengan permintaan tagihan untuk pembayaran. Halaman help yang disediakan juga mendapatkan respon yang positif dari responden. Aplikasi dinilai mudah digunakan dan responden sangat tertarik untuk menggunakannya. Terdapat komentar dan saran dari responden untuk pengembangan aplikasi selanjutnya. 


\section{SIMPULAN}

Berdasarkan evaluasi, aplikasi Xserve dapat membantu dan memudahkan customer dalam melakukan proses pemesanan makanan melalui fitur-fitur yang ada pada aplikasi seperti informasi promo, deskripsi menu, call waiter dan request bill serta menjawab permasalahan-permasalahan yang sering muncul ketika customer melakukan pemesanan makanan di restoran. Aplikasi pemesanan makanan dan layanan restoran XServe dilengkapi dengan fitur profil restoran, pencarian restoran supported terdekat, promo restoran, pencarian menu, rating restaurant by customer, rating menu by customer, multiple order in one bill dan call waiter sehingga memudahkan customer memilih restoran yang sesuai.

Dengan menggunakan sistem yang terintegrasi antara aplikasi pada smartphone dengan aplikasi backend proses operasional restoran dalam mengelola data menu, karyawan, dan transaksi menjadi lebih baik dan rapi sesuai dengan dengan delapan aturan emas dan memenuhi lima faktor manusia terukur yang dikemukakan oleh Shneiderman dan Plaisant (2010) serta sesuai dengan prinsip perancangan mobile application berdasarkan Stark (2012).

\section{DAFTAR PUSTAKA}

Almarogi, S. (2013). Ruang Lingkup Layanan Makanan dan Minuman. Diakses pada 5 Maret 2014 dari Ilmu Perhotelan : http://www.tasikhotel.com/2013/05/ruang-lingkup-layanan-makanandan.html

AndroidPIT. (2015). Android Apps Lifestyle QikServe. Diakses pada 10 Mei 2015 dari http://www.androidpit.com/app/com.qikserve

Law, C. \& So, S. (2010). QR Codes in Education. Journal of Educational Technology Development and Exchange, 3(1), 85-100.

Napitupulu, Paimin. (2007). Pelayanan Publik dan Customer Statisfiction.Bandung: PT. Alumni.

Ninemeir, J. D., \& Hayes, D. K. (2006). Restaurant Operations Management: Principles and Practices. Upper Saddle River, N.J: Pearson Prentice Hall.

Pressman, R. S. (2010). Software engineering: a practitioner's approach 7th edition. New York: McGraw-Hill.

Ratminto \&Winarsih, A.S.(2005). Manajemen Pelayanan. Yogyakarta: Pustaka Belajar.

Reynolds, D., Merritt,E.A., \& Pinckney, S. (2005). Understanding menu psychology: an empirical investigation of menu design and customer responseInt. J. Hosp. Tourism Adm., 6 (1) (2005), pp. 1-9

Shneiderman, B., \& Plaisant, C. (2010). Designing the User Interface: Strategies for Effective HumanComputer Interaction (5th Edition). USA: Addison-Wesley.

Sinambela, L. P. (2006). Reformasi Pelayanan Publik:Teori, Kebijakan,dan Implementasi. Jakarta: PT. BumiAksara.

Stark, J. (2012). The 10 Principles of Mobile Interface Design. Diakses pada 5 Maret 2014 dari http://www.netmagazine.com/features/10-principles-mobile-interface-design 